\title{
Expression and significance of SOX2 in non-small cell lung carcinoma
}

\author{
JIE YING ${ }^{1}, \mathrm{CHAO} \mathrm{SHI}^{2}, \mathrm{CHUAN-SHENG} \mathrm{LI}{ }^{1}$, LI-PING HU ${ }^{2}$ and WEI-DONG ZHANG ${ }^{3}$ \\ Departments of ${ }^{1}$ Infection, ${ }^{2}$ General Surgery and ${ }^{3}$ Cardiology, Xuyi People's Hospital, Xuyi, Jiangsu 211700, P.R. China
}

Received January 4, 2016; Accepted August 22, 2016

DOI: $10.3892 / \mathrm{ol} .2016 .5065$

\begin{abstract}
The aim of the present study was to examine the expression and clinical significance of SOX2 in non-small cell lung carcinoma (NSCLC). Immunohistochemistry was used to detect the expression level of SOX2 in 127 cases of NSCLC. The Chi-square test was used to analyze the association of SOX2 expression and clinicopathological factors in NSCLC and para-carcinoma tissues $(2.5 \%)$. The Kaplan-Meier method was applied to plot the survival curve, and the log-rank test and COX multiple regression model were applied to determine survival. SOX2 showed a high expression in $35.4 \%$ NSCLC tissues, which was significantly higher than that of the para-carcinoma tissues. The expression level of SOX2 was not associated with gender, age, smoking history or TNM stage $(\mathrm{P}>0.05)$, but was significantly associated with the pathological type of carcinoma. The high expression rate of SOX2 in lung squamous cell carcinoma was 50\% (25/50) and in lung adenocarcinoma was $20.3 \%$ (12/59). Survival analysis indicated that the prognosis of patients with a high SOX2 expression was significantly better than those with a low SOX 2 expression. The COX multiple regression analysis revealed that the expression level of SOX2 was an independent prognostic factor of patients with NSCLC $(\mathrm{P}<0.001)$. In conclusion, the expression of SOX2 in NSCLC tissues was upregulated, which was associated with the pathological type of carcinoma, while a high SOX2 expression mainly occurred in lung squamous cell carcinoma.
\end{abstract}

\section{Introduction}

Lung carcinoma is the leading malignant carcinoma with the highest mortality rate worldwide (1). The main pathological types of lung carcinoma are small cell lung carcinoma $(\sim 15 \%)$ and non-small cell lung carcinoma (NSCLC) ( 85\%). The common pathological types of NSCLC are lung squamous cell carcinoma ( $40 \%)$, lung adenocarcinoma ( 40\%) and lung

Correspondence to: Dr Jie Ying, Department of Infection, Xuyi People's Hospital, 28 Hongwu Road, Xuyi, Jiangsu 211700, P.R. China

E-mail: yj_8611@163.com

Key words: non-small cell lung carcinoma, SOX2, prognostic factors large-cell carcinoma ( 10\%) (2). Although the use of targeted agents in recent years has increased the survival rate of the NSCLC, it remains the severest malignant carcinoma with the poorest treatment effects (3).

Determination of the molecular mechanism underlying the occurrence and development of NSCLC, and the development of new therapeutic targets are important means for improving its poor therapeutic effect and low survival rate. Stem cell core transcription factor SOX2 is a member of the SOX (SRY-like HMG box) gene family, which includes HMG in the DNA-binding zone and plays an important role in maintaining the self-renewal, multi-differentiation and reprogramming of stem cells (4-6). The abnormal expression of SOX2 is associated with the occurrence and development of many malignant carcinomas, such as esophageal, breast, gastric and colon carcinoma (7-10). Previous findings showed that SOX2 is overexpressed in NSCLC, and its positive rate in lung squamous cell carcinoma is significantly higher than that in lung adenocarcinoma. However, the correlation of the overexpression of SOX2 and the prognosis of NSCLC remains controversial (11-14).

By means of immunohistochemical analysis, the aim of the present study was to examine the expression of SOX2 in the NSCLC of Chinese individuals and analyze the correlation of SOX2 expression, clinicopathological factors and prognosis.

\section{Patients and methods}

Patients and samples. A total of 127 patients with NSCLC that accepted radical resection of pulmonary carcinoma from January, 2007 to December, 2008 were included in the present study. None of the patients received neoadjuvant chemotherapy. Of the 127 patients, there were 101 males and 26 females of age between 39 and 75 years, with an average age of 57 years. All 127 patients were followed-up for $>60$ months. Paraffin specimens of carcinoma and para-carcinoma tissues were collected from the patients for tissue microarray. Each piece of tissue was set with three $2 \mathrm{~mm}$ repeat points. After hematoxylin and eosin staining, the specimens were analyzed and diagnosed by two chief physicians of the pathology department. In addition to tissue microarray, lung adenosquamous carcinoma tissues were also subjected to paraffin section and immunohistochemical staining. In the course of immunohistochemistry, no carcinoma tissue shed and 5 cases of carcinoma adjacent tissues shed. 
Immunohistochemistry. The SOX2 antibody was purchased from Bethyl Laboratories, Inc. (A301-741A; Montgomery, TX, USA). Immunohistochemical reagent (PV 9000 and DAB) coloring solution was purchased from Beijing Zhongshan Golden Bridge Biotechnology Co., Ltd. (Beijing, China). Tissue sections were dewaxed in xylene, hydrated in gradient ethanol $(100,95,90,85,80$ and $75 \%)$, placed in 3\% hydrogen peroxide and incubated for $10 \mathrm{~min}$ to block endogenous peroxidase. Subsequently, the sections were rinsed with phosphate-buffered saline 3 times, and incubated with 5\% goat serum at $25^{\circ} \mathrm{C}$ for $30 \mathrm{~min}$, followed by incubation with rabbit polyclonal SOX2 primary antibody (Abcam,Cambridge, MA, USA; catalog no. ab97959; dilution of $1: 500$ ) at $4^{\circ} \mathrm{C}$ overnight. The following day, the sections were incubated with PV 9000 at room temperature, and color was developed using DAB solution. After rinsing the slides in deionized water, the sections were counterstained with hematoxylin and decolorized with $1 \%$ hydrochloric acid, returned to blue following $1 \%$ ammonia and dehydrated with gradient ethanol before sealing.

Interpretation of immunohistochemical results. Tissue microarray staining results were read by two chief physicians from the Department of Pathology, Fujian Provincial Cancer Hospital (Fuzhou, China), independently. According to the staining degree of the nucleus, the sections were assigned a score of 0-4. According to the percentage of positive cells, the sections were scored as $0(\leq 5 \%), 1(6-25 \%), 2(26-50 \%)$, $3(51-75 \%)$, and $4(76-100 \%)$. According to the comprehensive scores of staining intensity and positive cell number, the sections were numbered as ' 0 ', indicating negative (-); '1-4', indicating positive $(+)$; '5-7', indicating positive $(++)$; $\geq 8$, indicating positive $(+++)$.

Statistical analysis. SPSS 18.0 statistical software (SPSS, Inc., Chicago, IL, USA) was used for statistical analysis. SOX2 expression and analysis of the clinicopathological factors were performed using the $\chi^{2}$ test. Survival analysis was performed using the Kaplan-Meier method and log-rank test. COX model was used to determine the multi-factor regression analysis of prognosis-related factors. $\mathrm{P}<0.05$ was considered to indicate a statistically significant difference.

\section{Results}

Expression of SOX2 in NSCLC tissues was higher than that in para-carcinoma tissues. The expression of SOX2 in NSCLC tissues showed 29 cases (22.8\%) of negative (-) expression, 53 cases $(41.7 \%)$ of positive $(+)$ expression, 28 cases $(22.8 \%)$ of positive $(++)$ expression, and 16 cases $(12.6 \%)$ of positive $(+++)$ expression. The expression of SOX 2 in para-carcinoma tissues showed 74 cases $(60.7 \%)$ of negative (-) expression, 45 cases $(36.9 \%)$ of positive $(+)$ expression, 3 cases $(2.5 \%)$ of positive $(++)$ expression, and 0 case of positive $(+++)$ expression. Positive (++) and (+++) was considered a high SOX2 expression, and negative (-) and positive (+) were considered a low SOX2 expression. The high expression rate of SOX2 in NSCLC tissues was significantly higher than that in para-carcinoma tissues (Table I). The difference was statistically significant $(\mathrm{P}<0.001)$.
Table I. Staining degree of SPX3 in non-small cell lung carcinoma and para-carcinoma tissues [case (\%)].

\begin{tabular}{lcccc}
\hline Group & Case & $\begin{array}{c}\text { Weakly } \\
\text { positive }\end{array}$ & $\begin{array}{c}\text { Strongly } \\
\text { positive }\end{array}$ & P-value \\
\hline Carcinoma & 127 & $82(64.6 \%)$ & $45(35.4 \%)$ & $<0.001$ \\
Normal mucosa & 122 & $119(97.6 \%)$ & $3(2.5 \%)$ & \\
\hline
\end{tabular}

Table II. Correlation between SOX2 expression and clinicopathological factors in patients with non-small cell lung carcinoma [case $(\%)]$.

SOX2 low SOX2 high

Variables Case expression expression P-value

\begin{tabular}{|c|c|c|c|c|}
\hline \multicolumn{5}{|l|}{ Gender } \\
\hline Male & 101 & $61(74.4)$ & $40(88.9)$ & \multirow[t]{2}{*}{0.066} \\
\hline Female & 26 & $21(25.6)$ & $5(11.1)$ & \\
\hline \multicolumn{5}{|l|}{ Age } \\
\hline$\geq 57$ years & 66 & $40(48.8)$ & $26(57.8)$ & \multirow[t]{2}{*}{0.358} \\
\hline$<57$ years & 61 & $42(51.2)$ & $19(42.2)$ & \\
\hline \multicolumn{5}{|l|}{$\begin{array}{l}\text { Smoking } \\
\text { history }\end{array}$} \\
\hline Yes & 56 & $32(39.0)$ & $24(53.3)$ & \multirow[t]{2}{*}{0.138} \\
\hline No & 71 & $50(61.0)$ & $21(46.7)$ & \\
\hline \multicolumn{5}{|l|}{ Pathological type } \\
\hline Adenocarcinoma & 59 & $47(57.3)$ & $12(26.7)$ & \multirow[t]{3}{*}{0.004} \\
\hline $\begin{array}{l}\text { Squamous } \\
\text { carcinoma }\end{array}$ & 50 & $25(30.5)$ & $25(55.6)$ & \\
\hline $\begin{array}{l}\text { Adenosquamous } \\
\text { carcinoma }\end{array}$ & 18 & $10(12.2)$ & $8(17.8)$ & \\
\hline \multicolumn{5}{|l|}{ T staging } \\
\hline $\mathrm{T} 1$ & 8 & $4(4.9)$ & $4(8.9)$ & \multirow[t]{3}{*}{0.273} \\
\hline $\mathrm{T} 2$ & 90 & $62(75.6)$ & $28(62.2)$ & \\
\hline T3 & 29 & $16(19.5)$ & $13(28.9)$ & \\
\hline \multicolumn{5}{|l|}{$\mathrm{N}$ staging } \\
\hline No & 47 & $31(37.8)$ & $16(35.6)$ & \multirow[t]{3}{*}{0.403} \\
\hline N1 & 31 & $17(20.7)$ & $14(31.1)$ & \\
\hline $\mathrm{N} 2$ & 49 & $34(41.5)$ & $15(33.3)$ & \\
\hline \multicolumn{5}{|l|}{ TNM staging } \\
\hline I & 38 & $26(31.7)$ & $12(26.7)$ & \multirow[t]{3}{*}{0.570} \\
\hline II & 30 & $17(20.7)$ & $13(28.9)$ & \\
\hline III & 59 & $39(47.6)$ & $20(44.4)$ & \\
\hline
\end{tabular}

Expression of SOX2 in NSCLC tissues was significantly correlated with the pathological type of carcinoma. The expression level of SOX2 was not associated with gender, age, smoking history or TNM stage, but was significantly associated with the pathological type of carcinoma. The high expression rate of SOX2 in lung squamous cell carcinoma was $50 \%(25 / 50)$ and in lung adenocarcinoma was $20.3 \%(12 / 59)$ (Table II), indicating that SOX2 high expression mainly occurred in lung squamous cell carcinoma. Of the 18 cases 

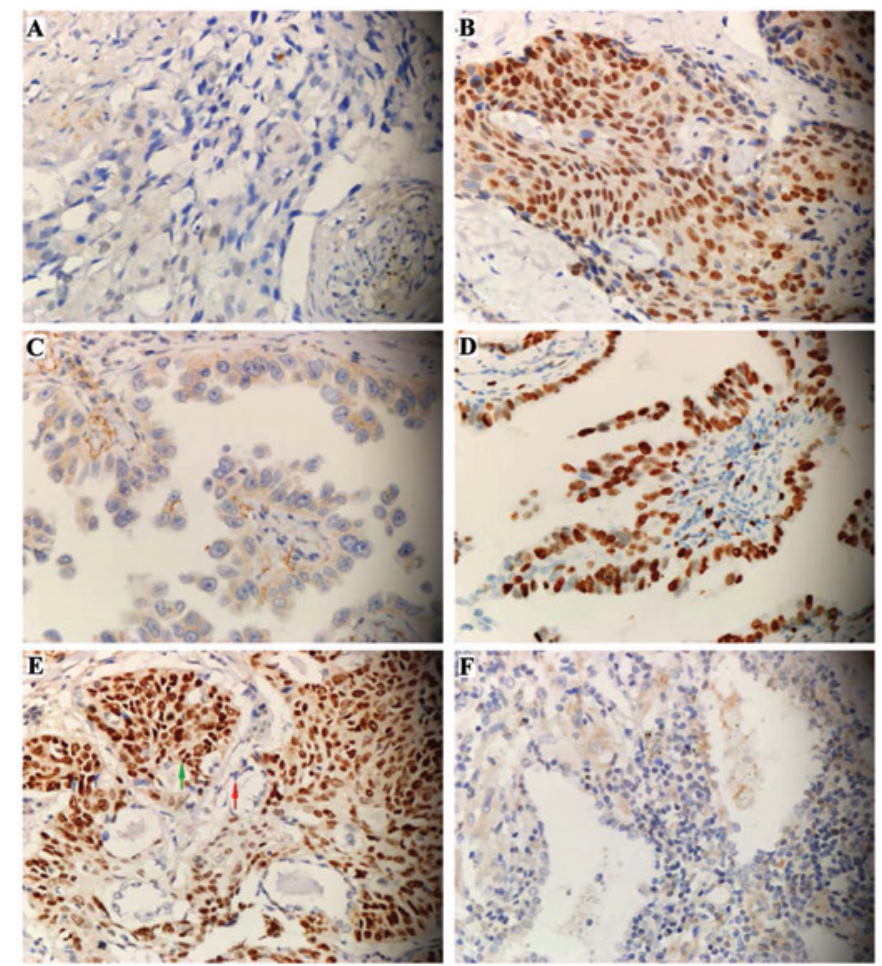

Figure 1. Expression of SOX2 in non-small cell lung carcinoma. (A and B) Expression of SOX2 in lung squamous carcinoma: (A) Negative (-), (B) strongly positive (+++). (C and D) Expression of SOX2 in lung adenocarcinoma: (C) Negative (-), (D) strongly positive (+++). (E) Expression of SOX2 in lung adenosquamous carcinoma: Weakly positive in adenocarcinoma cells (red arrow), strongly positive in squamous carcinoma (green arrow) (F) SOX2 shows a low expression in normal lung epithelial cells.

of high expression of lung adenosquamous carcinoma, SOX2 showed a high expression in the adenocarcinoma and squamous cell carcinoma cells of 1 adenosquamous carcinoma tissue. SOX2 also showed a high expression in squamous carcinoma cells and low expression in adenocarcinoma cells of 7 tissues. By contrast, SOX2 showed a low expression in adenocarcinoma and squamous cell carcinoma cells of 10 tissues (Fig. 1), confirming that the expression level of SOX2 was significantly associated with the pathological type of carcinoma. Additionally, the high expression rate of squamous cell carcinoma cells was significantly higher than that of adenocarcinoma cells.

Expression of SOX2 in NSCLC was correlated with the survival of patients. The Kaplan-Meier method was applied to plot the survival curve, and the log-rank test and COX multiple regression model were applied for estimation of the survival analysis. The prognosis of patients with a high SOX2 expression was significantly better than those with a low SOX2 expression (Fig 2). The COX multiple regression analysis revealed that $\mathrm{T}$ and $\mathrm{N}$ staging of the carcinoma was the same, indicating that the expression level of SOX2 was an independent prognostic factor of patients with NSCLC $(\mathrm{P}<0.001)$ (Table III).

\section{Discussion}

SOX2 protein is an important role in cell cycle regulation, DNA damage repair and maintaining the totipotency of stem
Table III. SOX2 expression level was an independent prognostic factor (COX multivariate regression analysis).

\begin{tabular}{|c|c|c|}
\hline Factors & $\begin{array}{c}\text { Relative risk } \\
(95 \% \mathrm{CI})\end{array}$ & P-value \\
\hline Gender (male/female) & $0.795(0.416-1.519)$ & 0.487 \\
\hline Age $(\geq 57 /<57$ years $)$ & $1.158(0.668-2.006)$ & 0.601 \\
\hline $\begin{array}{l}\text { Pathological type } \\
\text { (adenocarcinoma/ } \\
\text { adenosquamous carcinoma) }\end{array}$ & $1.325(0.945-1.859)$ & 0.102 \\
\hline $\mathrm{T}$ staging (T3/T2/T1) & $1.610(1.004-2.584)$ & 0.048 \\
\hline $\mathrm{N}$ staging (N2/N1/N0) & $2.036(1.527-2.714)$ & $<0.001$ \\
\hline $\begin{array}{l}\text { SOX2 expression } \\
\text { (high expression/ } \\
\text { low expression) }\end{array}$ & $0.380(0.223-0.649)$ & $<0.001$ \\
\hline
\end{tabular}

a'Adenocarcinoma' includes adenocarcinoma cases and adenosquamous carcinoma cases (15).

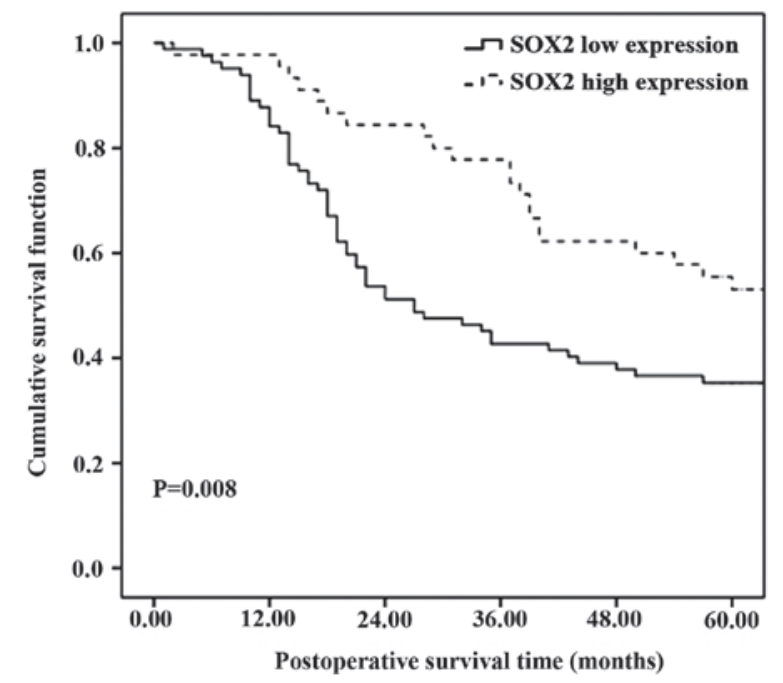

Figure 2. Association between SOX2 expression and prognosis of non-small cell lung carcinoma. Survival analysis revealed that the prognosis of patients of the high expression group was better $(\mathrm{P}=0.008)$ and the 5-year survival rate was higher (high vs. low: 55.5 vs. $35.3 \%$ ).

cells. In many malignant carcinomas, the high expression of SOX2 is associated with the invasion and poor prognosis of carcinoma $(7,8,16)$. However, at present, detailed information on the expression of SOX2 in the Chinese population of NSCLC is lacking. Previous studies have suggested that the occurrence and therapeutic targets of lung carcinoma in different ethnic groups are varied $(17,18)$. In this study, we mainly focused on examining the association of SOX2 expression and clinicopathological factors and prognosis of NSCLC of Chinese patients. The results of the present study showed that the expression of SOX2 in NSCLC tissues was higher than that in the para-carcinoma tissues and a high SOX2 expression mainly occurred in lung squamous cell carcinoma cells. The study results were consistent with those of European and Japanese investigators $(11,13)$. 
The results of our study also show that of the 18 cases of adenosquamous carcinoma, the positive rate of SOX2 expression in adenocarcinoma cells was higher than that in squamous cell carcinoma cells. The 7 cases showed a high SOX2 expression in squamous carcinoma cells and a low expression in adenocarcinoma cells, further confirming that the expression level of SOX2 was significantly associated with the pathological type of carcinoma. Additionally, SOX2 is a potential molecular marker for the diagnosis of lung squamous cell carcinoma. The study of Sasaki et al showed that the DNA copy number of SOX2 gene was increased significantly in lung squamous cell carcinoma, but no significant changes were found in lung adenocarcinoma (11), which indicated that the overexpression of SOX2 in lung squamous cell carcinoma may be caused by the increase of DNA copy number and the overexpression of SOX2 in some lung adenocarcinoma may be caused by other mechanisms, such as transcription level and post-ßtranscriptional modifications.

At present, the regulatory mechanism of SOX2 in carcinoma cells is not entirely clear. Existing research results have shown that as a nuclear transcription factor, SOX2 can induce the expression of squamous carcinoma labeled carcinoma-associated factor p63 and keratin 6, and activate the downstream epidermal growth factor receptor and insulin-like growth factor-1 signals, to promote the proliferation, invasion and migration of carcinoma cells $(7,8,16)$. Consequently, the high expression of SOX2 protein may lead to poor prognosis. However, consensus on the correlation of the expression of SOX 2 and the prognosis of NSCLC is lacking. Sholl et al (12) suggested that SOX2 overexpression was associated with the poor prognosis of stage I lung adenocarcinoma, whereas the study of Sasaki et al showed that there was no significant correlation of the SOX2 expression and prognosis of lung squamous cell carcinoma (11). Wilbertz et al (14) suggested that the expression of SOX 2 was associated with the prognosis of lung squamous cell carcinoma, and this expression suggested an improved prognosis. In a study using a large sample, Velcheti et al (13) found that SOX2 overexpression in NSCLC (squamous cell carcinoma and adenocarcinoma) was more favorable for prognosis than a low SOX2 expression, a finding which was consistent with the results of the present study. Nevertheless, since the regulation mechanism of SOX2 in carcinoma cells is not very clear, this result lacks a convincing explanation. In the present study as well as that of Velcheti et al (13), the majority of the subjects were in stage II and III and underwent chemotherapy and/or radiotherapy after surgery. In the study of Sholl et al (12), where patients were primarily in stage I and did not undergo chemotherapy and/or radiotherapy after surgery, the opposite result was obtained. Thus, a better prognosis caused by SOX 2 overexpression may be associated with the sensitivity of lung carcinoma cells to chemotherapy. The present study and that of Velcheti et al are retrospective studies, the postoperative adjuvant treatment plan was not unified, information obtained was not complete, and we cannot exclude the influence of postoperative adjuvant therapy on prognosis. Therefore, the sensitivity of SOX2 overexpression and carcinoma cells to radiotherapy and chemotherapy remains to be investigated.
There are some shortcomings to the present study, as we only used immunohistochemistry for detection and did not study the DNA copy number, or mRNA level of the genes. Most of the subjects were in stage II and III and required chemotherapy and/or radiotherapy after surgery. Since the present study was a retrospective one, adjuvant therapy after surgery was not strictly controlled, which may affect the analysis of prognosis. Additionally, the sample size was insufficient. These factors should be considered in future studies.

\section{References}

1. Jemal A, Bray F, Center MM, Ferlay J, Ward E and Forman D: Global cancer statistics. CA cancer J Clin 61: 69-90, 2011.

2. Hoffman PC, Mauer AM and Vokes EE: Lung cancer. Lancet Oncol 355: 479-485, 2000.

3. Bruera S, Shete E, McDevitt J, Kelly M, Wang LK, Hong TM and Chen HY: Surgery for non-small cell lung cancer. Asian Pac J Surg Oncol 1: 157-170, 2015.

4. Que J, Luo X, Schwartz RJ and Hogan BL: Multiple roles for Sox2 in the developing and adult mouse trachea. Development 136: 1899-1907, 2009.

5. Gontan C, de Munck A, Vermeij M, Grosveld F, Tibboel D and Rottier R: Sox2 is important for two crucial processes in lung development: Branching morphogenesis and epithelial cell differentiation. Dev Biol 317: 296-309, 2008.

6. Graham V, Khudyakov J, Ellis P and Pevny L: SOX2 functions to maintain neural progenitor identity. Neuron 39: 749-765, 2003.

7. Long KB and Hornick JL: SOX2 is highly expressed in squamous cell carcinomas of the gastrointestinal tract. Hum Pathol 40: 1768-1773, 2009.

8. Maier S, Wilbertz T, Braun M, Scheble V, Reischl M, Mikut R, Menon R, Nikolov P, Petersen K, Beschorner C, et al: SOX2 amplification is a common event in squamous cell carcinomas of different organ sites. Hum Pathol 42: 1078-1088, 2011.

9. Lengerke C, Fehm T, Kurth R, Neubauer H, Scheble V, Müller F, Schneider F, Petersen K, Wallwiener D, Kanz L, et al: Expression of the embryonic stem cell marker SOX2 in early-stage breast carcinoma. BMC cancer 11: 42, 2011.

10. Neumann J, Bahr F, Horst D, Kriegl L, Engel J, Luque RM, Gerhard M, Kirchner T and Jung A: SOX2 expression correlates with lymph-node metastases and distant spread in right-sided colon cancer. BMC Cancer 11: 518, 2011.

11. Sasaki H, Yokota K, Hikosaka Y, Moriyama S, Yano M and Fujii Y: Increased Sox2 copy number in lung squamous cell carcinomas. Exp Ther Med 3: 44-48, 2012.

12. Sholl LM, Barletta JA, Yeap BY, Chirieac LR and Hornick JL: Sox 2 protein expression is an independent poor prognostic indicator in stage I lung adenocarcinoma. Am J Surg Pathol 34: 1193-1198,2010.

13. Velcheti V, Schalper K, Yao X, Cheng H, Kocoglu M, Dhodapkar K, Deng Y, Gettinger S and Rimm DL: High SOX2 levels predict better outcome in non-small cell lung carcinomas. PLoS One 8: e61427, 2013.

14. Wilbertz T, Wagner P, Petersen K, Stiedl AC, Scheble VJ, Maier S, Reischl M, Mikut R, Altorki NK, Moch H, et al: SOX2 gene amplification and protein overexpression are associated with better outcome in squamous cell lung cancer. Mod Pathol 24: 944-953, 2011.

15. Brock MV, Hooker CM, Ota-Machida E, Han Y, Guo M, Ames S, Glöckner S, Piantadosi S, Gabrielson E, Pridham G, et al: DNA methylation markers and early recurrence in stage I lung cancer. N Engl J Med 358: 1118-1128, 2008.

16. Ge N, Lin HX, Xiao XS, Guo L, Xu HM, Wang X, Jin T, Cai XY, Liang Y, Hu WH, et al: Prognostic significance of Oct4 and Sox2 expression in hypopharyngeal squamous cell carcinoma. J Transl Med 8: 94, 2010.

17. Cataldo VD, Gibbons DL,Pérez-Soler R and Quintás-Cardama A: Treatment of non-small-cell lung cancer with erlotinib or gefitinib. N Engl J Med 364: 947-955, 2011.

18. Shaw AT, Kim DW, Nakagawa K, Seto T, Crinó L, Ahn MJ, De Pas T, Besse B, Solomon BJ, Blackhall F, et al: Crizotinib versus chemotherapy in advanced ALK-positive lung cancer. N Engl J Med 368: 2385-2394, 2013. 